Dokuz Eylül Üniversitesi-Mühendislik Fakültesi

Fen ve Mühendislik Dergisi

Cilt 19, Sayı 57, Eylül 2017
Dokuz Eylul University-Faculty of Engineering Journal of Science and Engineering Volume 19, Issue 57, September 2017

DOI: $10.21205 /$ deufmd.2017195763

\title{
Montmorillonit Mineral Kayacı Kullanılarak Çözeltilerden Krom (III) İyonlarının Giderimi ve Etki Eden Parametrelerin İncelemesi
}

\author{
Şahset İRDEMEZ*1 ${ }^{\mathbf{1}}$, Fatma EKMEKYAPAR TORUN ${ }^{1}$, Gül DURMUȘ ${ }^{1}$ \\ ${ }^{1}$ Atatürk Üniversitesi, Mühendislik Fakültesi, Çevre Bölümü, Erzurum
}

(Alınış / Received: 09.01.2017, Kabul / Accepted: 21.04.2017, Online Yayınlanma / Published Online: 20.09.2017)

Anahtar Kelimeler Adsorpsiyon Krom (III) giderimi Montmorillonit
Özet: Bu çalışmada, Erzurum' un Narman ilçesinden temin edilen doğal kil montmorillonit ile sentetik olarak hazırlanmış krom (III) içeren sulardan adsorpsiyonla krom giderimi çalıșılmıștır. Çalışmada adsorpsiyona etki eden parametreler incelenmiş ve optimum değerler tespit edilmiştir. Ayrıca aynı adsorban aktifleştirilerek krom (III) giderimine yönelik denemeler tekrarlanmıștır.

Parametre olarak atıksuyun pH'sı, adsorban konsantrasyonu, başlangıç krom (III) konsantrasyonu, sıcaklık, karıştırma hızı incelenmiştir. Çalışma sonucunda en uygun $\mathrm{pH}=5$, en uygun karıştırma hızı $=300 \mathrm{rpm}$ olarak bulunmuştur. Sonuç olarak uygun $\mathrm{pH}$, adsorban konsantrasyonu, sıcaklık ve karıştırma hızı kullanıldığında \%90'a kadar giderme verimlerine ulaşılmıştır.

Aktifleştirme işleminin verime herhangi bir olumlu katkı yapmadığı hatta aktifleştirme işleminin por yapısını bozması nedeniyle desorpsiyonun hızlandığı tespit edilmiștir.

\section{The Removal of Chromium (III) Ions From Solutions and Examination of Effectig Parameters by Using Montmorillonit Mineral Clays}

\begin{tabular}{l}
\hline Keywords \\
Adsorption \\
Chromium (III) emoval \\
Montmorillonit
\end{tabular}

Chromium (III) emoval

\begin{abstract}
In this study, the removal of chromium (III) from waters by adsorption has been investigated using the natural clay, montmorillonit which was obtained from the vicinity of Narman, Erzurum. The effective parameters on adsorption were investigated and the optimal values were obtained. Same adsorbent has been tested at activation process and experiment were repeated.
\end{abstract}

The $\mathrm{pH}$, adsorbent concentration, initial chromium (III) concentration, temperature, stirring speed were examined as parameters. In conclusion, it has been found the optimal $\mathrm{pH}=5$, the optimal stirring speed $=300 \mathrm{rpm}$. It has been 
Ş. İrdemez vd. / Montmorillonit Mineral Kayacı Kullanılarak Atıksulardan Krom (III) İyonlarının Giderimi Etki Eden Parametrelerin İncelemesi

reached up to $\% 90$ of removal under the conditions of which appropriate $\mathrm{pH}$, adsorbent concentration, temperate and stirring speed were employed.

It was also determined that activation process has no positive effects on the yield. Because activation process increases the desorption by damaging the structure of the adsorbent.

*Sorumlu yazar: sirdemez@atauni.edu.tr

\section{Giriş}

Günümüzde dünya nüfusundaki hızlı artış, düzensiz kentleșme, enerji ve besin yetersizliği, tüketimin artması ve teknolojinin hızla gelișmesi, çevre kirliliği sorununun önemini iyice artırmıştır. Atık sular fiziksel, kimyasal ve biyolojik kirlilik gösterebilirler. Tekstil, kâğıt, deri, boya ve metal eşya endüstrisi gibi çeşitli endüstri atık suları fazla miktarda ağır metal ve sentetik boya içermektedir. Ağır metal ve sentetik boya içeren endüstriyel atık suların arıtımlarının yapılmadan akarsu ve denizlere boşaltılmasının bu ortamdaki canlılar üzerinde toksikkanserojen aromatik amin bileșiklerinin oluşması gibi birincil çevresel etkisinin yanında, estetik açıdan çevreyi olumsuz biçimde etkilemesi gibi ikincil bir etkisi de vardır.

Ağır metaller, su kaynaklarına en fazla endüstriyel faaliyetler (termik santraller, oto sanayi vs.), endüstriyel atıklar veya asit yağmurları ile ulaşabilmektedir. Asit yağmurlarının yağması toprakta bulunan ağır metallerin göllere, akarsulara ve denizlere karışmasına sebep olur. Asit yağmurları nedeniyle artan asitlik ve artan ağır metal konsantrasyonu suda yasayan canlılar için doğrudan zehir etkisi yapar.

Ayrıca ağır metal konsantrasyonunun yüksek olması oksijenin çözünürlüğünü düşürdüğünden ağır metal içeren atık suların su kaynaklarına arıtımı yapılmadan boşaltılması, çözünmüş oksijen miktarını azaltarak canlıları etkilemektedir. Türkiye'de kontrolsüz endüstrileşmeye izin verilmesi nedeni ile su kaynaklarındaki ve atmosferdeki ağır metal konsantrasyonları sürekli yükselmektedir. Ağır metallerin ekolojik sistemde doğal yollarla yayınımları dikkate alındığında insan faktöründen kaynaklanan ağır metal miktarlarının oldukça yüksek olduğu görülmektedir [1, 2].

Krom hem metalik olarak ve hem de bileşikleri şeklinde endüstride çok yaygin kullanılan bir metaldir. Krom paslanmaz çelik üretimi, çeşitli lehim ve pas engelleyicilerin üretimi ile ilgili metalürji endüstrisinde, boya, cila, cam ve seramik malzemelerinde, deri endüstrisinde kullanılmaktadır [3]. Bu nedenle bu endüstrilerin atık sularında önemli bir kirliliğe yol açmaktadırlar. Krom toksik özelliklere sahip olduğundan su ortamında bulunması istenmeyen bileşiklerdendir. Krom suların içerisinde hem +3 ve hem de +6 değerlikli olarak bulunabilir. Krom(VI) sularda kromatlar şeklinde anyon olarak bulunurken krom (III) katyon şeklinde bulunmaktadır. Bu nedenle giderim mekanizmaları farklıdır.

Çevre mühendisliğinde kullanılan en yaygin adsorban olan aktif karbon atık sulardan adsorpsiyonla krom gideriminde de en ideal adsorban olarak dikkat çekmektedir. Ancak, aktif karbonun pahalı bir malzeme olması nedeniyle daha düşük maliyetli 
Ş. İrdemez vd. / Montmorillonit Mineral Kayacı Kullanılarak Atıksulardan Krom (III) İyonlarının Giderimi Etki Eden Parametrelerin İncelemesi

adsorbanlar bulmak amacıyla çalıșmalar yapılmaktadır [4, 5]. Mineral esaslı doğal adsorbanların ve endüstri kaynaklı atıkların adsorban olarak kullanımında ise en önemli yönlerinin yüzeylerinde aktif merkezlerin bulunması, belirli bir iyon için seçici olmalarıdır [6].

Adsorpsiyon ișlemi özellikle düșük konsantrasyonlardaki krom içerikli atıksuların arıtımında uygun bir yöntem olarak dikkat çekmektedir. 1976'da Barlet ve Kimble [7] ve 2008 yılında Jiang [8] toprak materyalleri ile Griffin ve Frost 1977 [9] yılında kil ile 1975 yılında Huang [10] ve 2007 yılında Chen [11] aktif karbon ile 1978 yılında Kaneko [12] silika titania jeli ile 2005 yılında Majdan [13] bentonit ile 2000 yılında Toprak [14] aktifleștirilmiş klinoptilolit ile 2001 yılında Krishna [15] modifiye edilmiş aktif karbon ile 1999 yllında Günaydın [16] çinko ekstraksiyon artıkları ile 2004 yılında Erdem, Altundoğan and Tümen [17] aktive edilmiş boksit ile ve 1987 yılında Tümen, Arslan ve Bildik [18] kırmızı çamur ile çalışmalar yapmışlardır. 2016 yılında Samson ve arkadaşları [19] modifiye edilmiş yer fistığı kabuğu kullanarak, 2017 yılında Fellenz ve arkadașları [20] MCM-41 sorbenti kullanarak sulardan krom (VI) giderimi ile ilgili çalışmalar yapmışlardır.

Montmorillonit minerali ile literatürde birçok çalışma mevcuttur. Ancak krom (III) giderimi ile ilgili çalışmaya rastlanmamıştır.

$\mathrm{Bu}$ çalıșmada, Erzurum'un Narman ilçesinde bol miktarda bulunan bir mineral olan montmorillonit ile krom(III) içeren atık suların giderimi araştırılmıştır. Krom giderimine etki eden parametreler ve optimum değerleri tespit edilmiştir. Ayrıca aynı adsorban aktifleștirilerek aktifleştirme işleminin etkisi incelenmiştir.

\section{Materyal ve Metot}

Çalışmada sentetik olarak hazırlanmış atıksulardan krom(III) iyonlarının adsorpsiyonla giderimi ve adsorpsiyon üzerine etkili olan parametreler incelenmiștir. Çalıșmada Erzurum'un Narman ilçesinden çıkarılan doğal kil montmorillonit adsorban olarak kullanılmıştır. Deneysel çalışmada adsorpsiyon üzerine pH'ın etkisi, başlangıç krom konsantrasyonu, sıcaklık, karıştırma hızı ve adsorban miktarının etkisi incelenmiştir.

\subsection{Materyal}

\subsubsection{Kullanılan kil ve özellikleri}

$\mathrm{Bu}$ çalıșmada, Erzurum'un Narman ilçesinden çıkarılan doğal kil kullanılmıștır. Kilin kimyasal analiz sonuçları Tablo 1 ve Tablo 2'de verilmiştir [21].

Tablo 1. Mikronize montmorillonit mineral kayaç analizleri

\begin{tabular}{|c|c|}
\hline $\mathrm{Sembol}$ & $\%$ \\
\hline $\mathrm{Na}_{2} \mathrm{O}$ & $0,2-2,30$ \\
\hline $\mathrm{MgO}$ & $2,82-7,2$ \\
\hline $\mathrm{Al}_{2} \mathrm{O}_{3}$ & $20,6-13,7$ \\
\hline $\mathrm{SiO}_{2}$ & $45,1-8,2$ \\
\hline $\mathrm{K}_{2} \mathrm{O}$ & $0,82-2,6$ \\
\hline $\mathrm{CaO}$ & $1,71-7,4$ \\
\hline $\mathrm{TiO} \mathrm{O}_{2}$ & $0,52-0,63$ \\
\hline $\mathrm{Fe}_{2} \mathrm{O}_{3}$ & $5,62-6,13$ \\
\hline $\begin{array}{c}\text { LOI(Oksijen sinirlama } \\
\text { indeksi) }\end{array}$ & $12-13$ \\
\hline
\end{tabular}

Tablo 2. Montmorillonit mineralinin kimyasal analizi

\begin{tabular}{|l|l|}
\hline İçerik & $\%$ \\
\hline Semektit \% & $68-78$ \\
\hline Kaolin \% & $15-20$ \\
\hline Kil & 94 \\
\hline Kuars\% & 4 \\
\hline Diğer & 2 \\
\hline
\end{tabular}


Ş. İrdemez vd. / Montmorillonit Mineral Kayacı Kullanılarak Atıksulardan Krom (III) İyonlarının Giderimi Etki Eden Parametrelerin İncelemesi

\subsection{Metot}

Denemeler Admond Buhler KS-15 marka çalkalayıcı inkübatörde kesikli olarak gerçekleştirilmiştir. Krom (III) analizleri SHIMADZU AA6800 model atomik adsorpsiyon spektrofotometresi ile yapılmıştır. Tüm deneyler 250 ml'lik erlenlere $100 \mathrm{ml}$ atıksu konularak gerçekleștirilmiştir. Denemelerde kullanılan Cr(III) çözeltisi CARLO ERBA marka $\mathrm{Cr}\left(\mathrm{NO}_{3}\right)_{3} .9 \mathrm{H}_{2} \mathrm{O}$ ile hazırlanmıștır.

Aktifleştirme işlemi: Aktifleştirme işleminin uygulanacağ suyunda birkaç kez yıkanmıștır. Daha sonra birkaç kez de saf su ile yıkanarak $105^{\circ} \mathrm{C}^{\prime}$ de 4 saat bekletilmiştir. Kuruyan kil (ağırlıkça \%85) 1:1 oranında seyreltilmiş fosforik asitle muamele edilmiștir. Daha sonra $500^{\circ} \mathrm{C}^{\prime}$ de 2 saat kül fırınında bekletilmiştir. Daha sonra sıcak saf su ile pH 6 olana kadar yıkanmıș ve kurutularak küçük parçalar halinde cam şişeye konulmuştur [22].

\section{Bulgular}

3.1. Doğal (işlem Görmemiş)

Montmorillonit Kullanılarak Krom(III) iyonlarının Adsorpsiyonu

\subsection{1. pH'nın etkisi}

Montmorillonit minerali ile krom (III) giderilmesinde pH'nın etkisi incelenirken yapılan denemeler 100 $\mathrm{mg} / \mathrm{L} \mathrm{Cr}^{+3}$ içeren sentetik olarak hazırlanmış çözelti ve $5 \mathrm{gr} / \mathrm{L}$ adsorban konsantrasyonunda, $100 \mathrm{ml}$ çözelti ve 200 rpm karıștırma hızında gerçekleştirilmiştir. Deneyler süresince numuneler alınmıș ve elde edilen veriler Şekil 1' de şematik olarak gösterilmiștir.

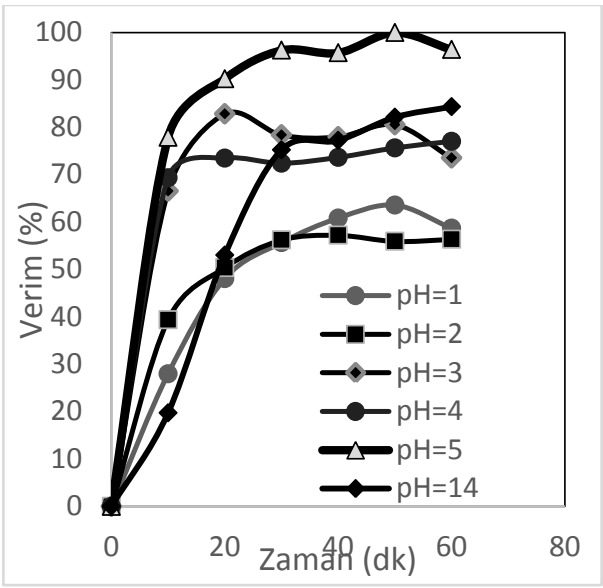

Şekil 1. $\mathrm{Cr}^{+3}$ ün montmorillonit üzerine adsorpsiyonuna $\mathrm{pH}$ 'nın etkisi

Şekil 1 incelendiğinde $\mathrm{pH} 1$ ve 2 için krom(III) gideriminin yaklaşık \%50, pH 3 ve 4 için yaklaşık $\% 80$ olduğu görülmektedir. pH 5'de ise \%100' e yakın verim elde edilmiştir. $\mathrm{pH} 6$ ile $\mathrm{pH}$ 12 arasında \%100 krom giderimi gerçekleşmiş olsa bile yapılan çalışmalar bu durumun büyük oranda adsorpsiyon ile değil kromun $\mathrm{Cr}(\mathrm{OH})_{3}$ şeklinde çökmesi şeklinde gerçekleştiği tespit edilmiștir. $\mathrm{Bu}$ nedenle bu $\mathrm{pH}$ aralığı dikkate alınmamıștır. pH 14'de ise krom (III)'ün çözünürlüğü yüksek olduğundan bu pH'da giderim kimyasal çöktürme ile değil adsorpsiyonla gerçekleşmiştir. $\mathrm{pH}=14$ için giderim $\% 80$ civarlarındadır.

$\mathrm{Bu}$ sebepten dolayı kimyasal çökelmenin önüne geçebilmek ve adsorpsiyonu inceleyebilmek amaciyla daha sonraki denemeler pH 5'de gerçekleştirilmiştir. 
Ş. İrdemez vd. / Montmorillonit Mineral Kayacı Kullanılarak Atıksulardan Krom (III) İyonlarının Giderimi Etki Eden Parametrelerin İncelemesi

\subsubsection{Sıcaklığın etkisi}

Montmorillonit minerali ile krom (III) giderilmesinde sıcaklığın etkisinin incelenmesi amaciyla yapılan denemeler $100 \mathrm{mg} / \mathrm{L} \mathrm{Cr} \mathrm{Cr}^{+3}, 5 \mathrm{gr} / \mathrm{L}$ adsorban konsantrasyonunda, $100 \mathrm{ml}$ çözelti kullanılarak, 200 rpm karıştırma hızında ve $\mathrm{pH}=5$ 'de gerçekleştirilmiştir. Deneyler süresince numune alınarak elde edilen veriler Şekil 2'de şematik olarak gösterilmiștir.

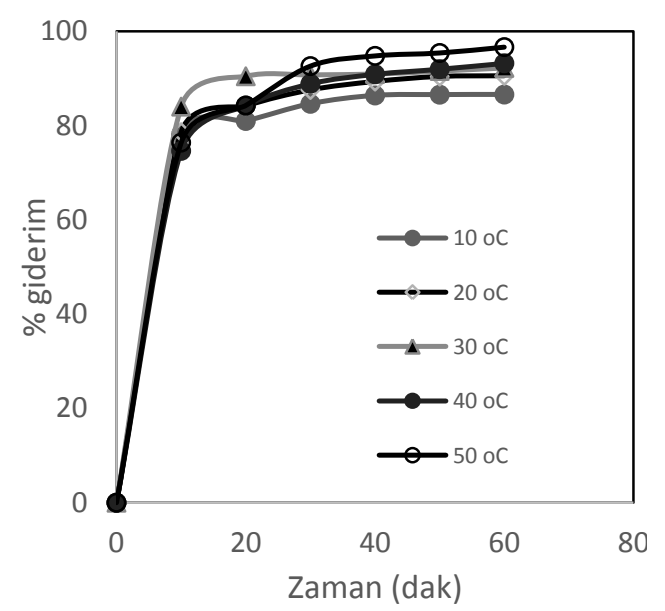

Şekil 2. $\mathrm{Cr}^{+3}$ 'ün montmorillonit üzerine adsorpsiyonuna sıcaklığın etkisi

Şekil 2 incelendiğinde bütün sıcaklık değerlerinde 10 dakikada yaklaşık $\% 80$ verime ulașıldığı görülmektedir. $10^{\circ} \mathrm{C}$ ' de 60 dakikada $\% 85$ verim elde edilirken 20,30 ve $40^{\circ} \mathrm{C}^{\prime}$ de 60 dakikada $\% 90$ verim elde edilmiştir. $50^{\circ} \mathrm{C}^{\prime}$ de 60 dakika da \%95 verime ulaşılmıștır. Şekil 2 'den elde edilen veriler kullanılarak yalancı ikinci derece kinetiğe göre reaksiyon hız sabitleri hesaplanmış ve $1 / T^{\prime}$ ye karşı ln k grafikleri çizilerek aktivasyon enerjisi 39,97 kJ/mol olarak bulunmuştur. $\mathrm{Bu}$ ise adsorpsiyon mekanizmasının fiziksel olduğunu göstermektedir.

\subsubsection{Karıștırma Hızının Etkisi}

Montmorillonit minerali ile krom(III) giderilmesinde karıştırma hızının etkisinin incelenmesi amaciyla yapılan denemeler $100 \mathrm{mg} / \mathrm{L} \mathrm{Cr}^{+3}, \quad 5 \mathrm{gr} / \mathrm{L}$ adsorban konsantrasyonunda ve $\mathrm{pH}=5$ 'de gerçekleştirilmiștir. Numuneler $100,200,300$ ve $400 \mathrm{rpm}$ karıștırma hızlarında 60 dakika işleme tabi tutulmuşlardır. Elde edilen veriler şekil 3'de gösterilmiştir.

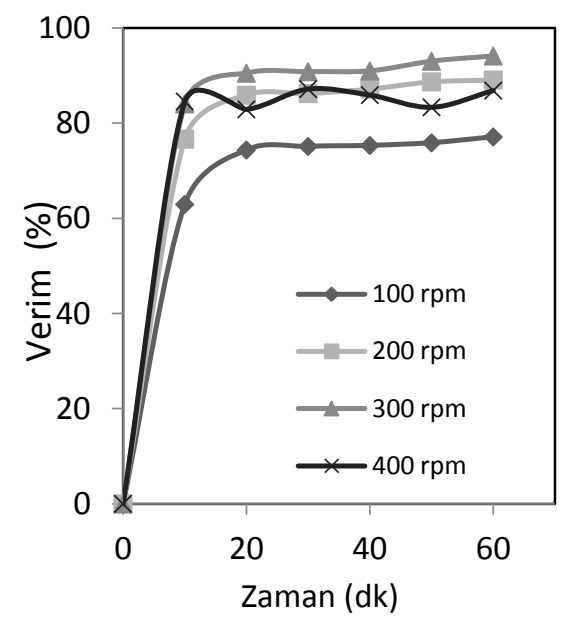

Şekil 3. $\mathrm{Cr}^{+3}$ 'ün montmorillonit üzerine adsorpsiyonuna karıștırma hızının etkisi

Illk 10 dakikada işleme tabi tutulan bütün karıștırma hızlarında yaklașık aynı verim elde edilmiştir. 10 dakikadan sonra düşük karıştırma hızlarında adsorbanın dibe çökmesi ve $\mathrm{Cr}^{+3}$ partikülleriyle yeterince temas edememesi nedeniyle yeterince verim elde edilememiştir. $100 \mathrm{rpm}$ karıștırma hızında verim yaklaşık \%70 olurken, 200 rpm'de $\% 85$ ve 300 rpm'de ise $\% 95$ olarak bulunmuştur. 400 rpm'de ise yüksek karıştırma hızı nedeniyle desorpsiyon meydana gelmiştir. Yapılan çalışmalarda en iyi verimi $300 \mathrm{rpm}$ karıştırma hızında elde edilmiştir. Bu 
Ş. İrdemez vd. / Montmorillonit Mineral Kayacı Kullanılarak Atıksulardan Krom (III) İyonlarının Giderimi Etki Eden Parametrelerin İncelemesi

nedenle diğer çalışmalar 300 rpm karıştırma hızında gerçekleştirilmiştir.

\subsubsection{Adsorban miktarının etkisi}

Montmorillonit minerali ile krom(III) iyonlarının adsorpsiyon prosesi kullanılarak giderilmesinde adsorban konsantrasyonunun etkisini incelemek amacıyla yapılan denemeler $100 \mathrm{mg} / \mathrm{L}$ $\mathrm{Cr}^{+3}$ konsantrasyonunda, $300 \mathrm{rpm}$ karıştırma hızında ve $\mathrm{pH}=5^{\prime}$ de gerçekleştirilmiştir. Denemelerde 0,1 gr/L; 0,5 gr/L; 1 gr/L; 2 gr/L; 5 gr/L ve $10 \mathrm{gr} / \mathrm{L}$ konsantrasyonlarında adsorban ilave edilmiş ve elde edilen veriler şekil 4'de gösterilmiştir.

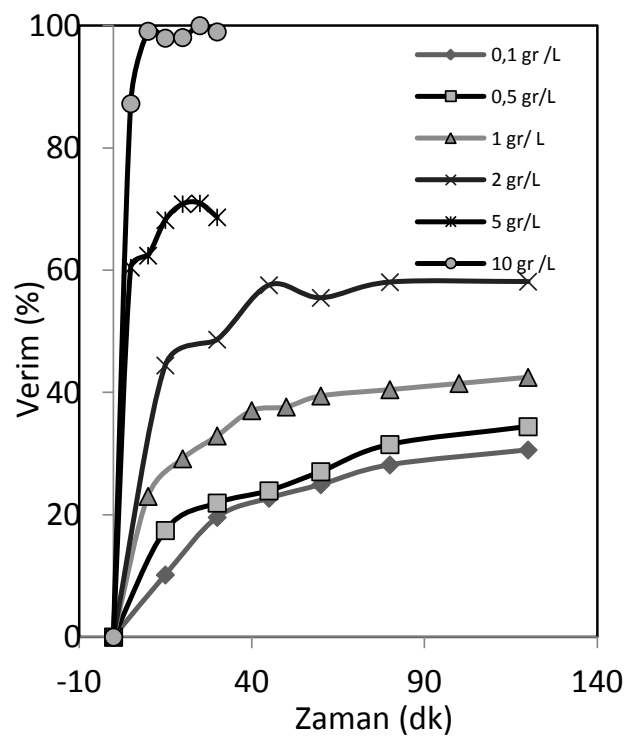

Şekil 4. $\mathrm{Cr}^{+3}$ 'ün montmorillonit üzerine adsorpsiyonuna adsorban miktarının etkisi

Yapılan çalışmalardan elde edilen sonuçlar adsorbanın 0,1 ve 0,5 gr/L kullanımında yaklaşık aynı verime ulaşıldığını göstermiștir. Adsorbanın 1 gr/L kullanımında yaklaşık \%40 verim elde edilmiştir. $2 \mathrm{gr} / \mathrm{L}$ adsorban kullanıldığında yaklaşık \%60'lık verime ulaşılmıştır. Adsorban $5 \mathrm{gr} / \mathrm{L}$ kullanıldığı zaman ilk dakikalarda verim \%60'a ulașmıș, 30 dakika sonunda ise verim \%70 olarak elde edilmiștir. 10 gr/L adsorban kullanıldığı zaman 20 dakikada \%100 verim elde edilmiştir. $\mathrm{Bu}$ sonuçlar adsorban konsantrasyonu arttıkça adsorpsiyon veriminin arttığını göstermektedir.

\subsubsection{Başlangıç Krom(III) Konsantrasyonun Etkisi}

Montmorillonit minerali ile krom(III) giderilmesinde başlangıç krom konsantrasyonu etkisi incelenirken 3 farkl adsorban konsantrasyonu kullanılmıştır. Deneyler 300 rpm karıștırma hızında ve 60 dakika temas süresinde gerçekleştirilmiştir. $5 \mathrm{gr} / \mathrm{L}$ adsorban konsantrasyonu için farklı konsantrasyonlarda krom(III) içeren çözeltilerle adsorpsiyonla giderim deneyleri ile elde edilen sonuçlar Şekil 5 'de verilmiştir.

$\mathrm{Bu}$ grafik incelendiğinde aynı adsorban konsantrasyonu için başlangıç krom konsantrasyonu arttıkça adsorpsiyon veriminin düştüğü söylenebilir. Fakat adsorpsiyonun dengeye gelme süresi değişmemektedir. Bu da adsorpsiyonun hızlı bir şekilde gerçekleştiğini göstermektedir. 
Ş. İrdemez vd. / Montmorillonit Mineral Kayacı Kullanılarak Atıksulardan Krom (III) İyonlarının Giderimi Etki Eden Parametrelerin İncelemesi

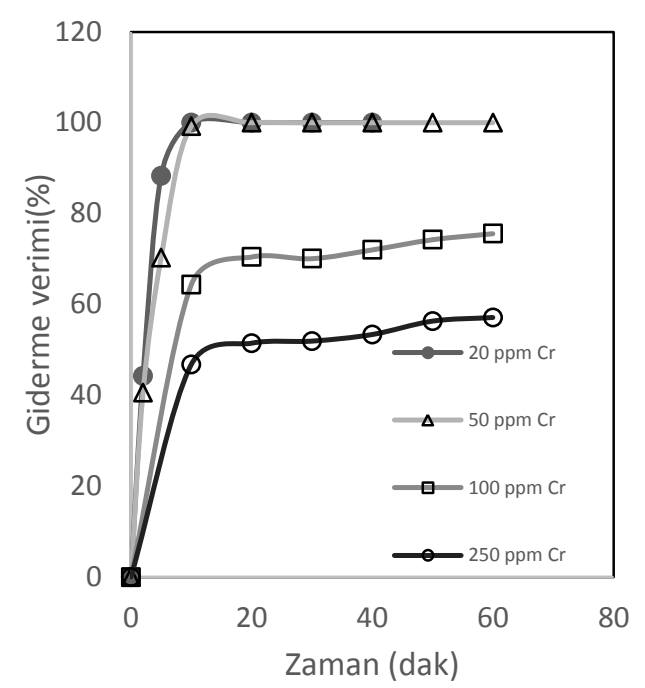

Şekil 5. $\mathrm{Cr}^{+3}$ 'ün montmorillonit üzerine adsorpsiyonuna başlangıç konsantrasyonunun etkisi

\subsection{Cr+3'ün Aktifleştirilmiş Doğal Kil Kullanılarak Adsorpsiyonu}

Herhangi bir işleme tabi tutulmamış doğal kil montmorillonit ile yapılan adsorpsiyon çalışmaları aktifleştirme işlemi uygulanarak da yürütülmüştür. Deney şartları aynı tutularak yapılan $\mathrm{pH}$ denemeleri Şekil 7'de mukayeseli olarak gösterilmiştir.

Şekil 7(a) incelendiğinde aktifleştirme işleminin özellikle düşük pH'larda verimi düşürdüğü yüksek pH'larda ise verimin hemen hemen aynı olduğu görülmektedir. pH 7-13 arasındaki pH'larda krom gideriminin adsorpsiyondan çok kimyasal çöktürme olduğu göz önüne alındığında bu pH'larda her iki adsorban için de verim \%100 bulunmuştur.
Diğer parametreler de tek tek incelendiği zaman aktifleştirme işleminin verime bir katkısı olmadığı ve hatta düşürdüğü görülmektedir. Özellikle karıştırma hızında aktifleştirme işleminin verimi düşürdüğü dikkate alınırsa bu işlemin adsorbentin por yapısını bozduğu görülmektedir. 
Ş. İrdemez vd. / Montmorillonit Mineral Kayacı Kullanılarak Atıksulardan Krom (III) İyonlarının Giderimi Etki Eden Parametrelerin İncelemesi

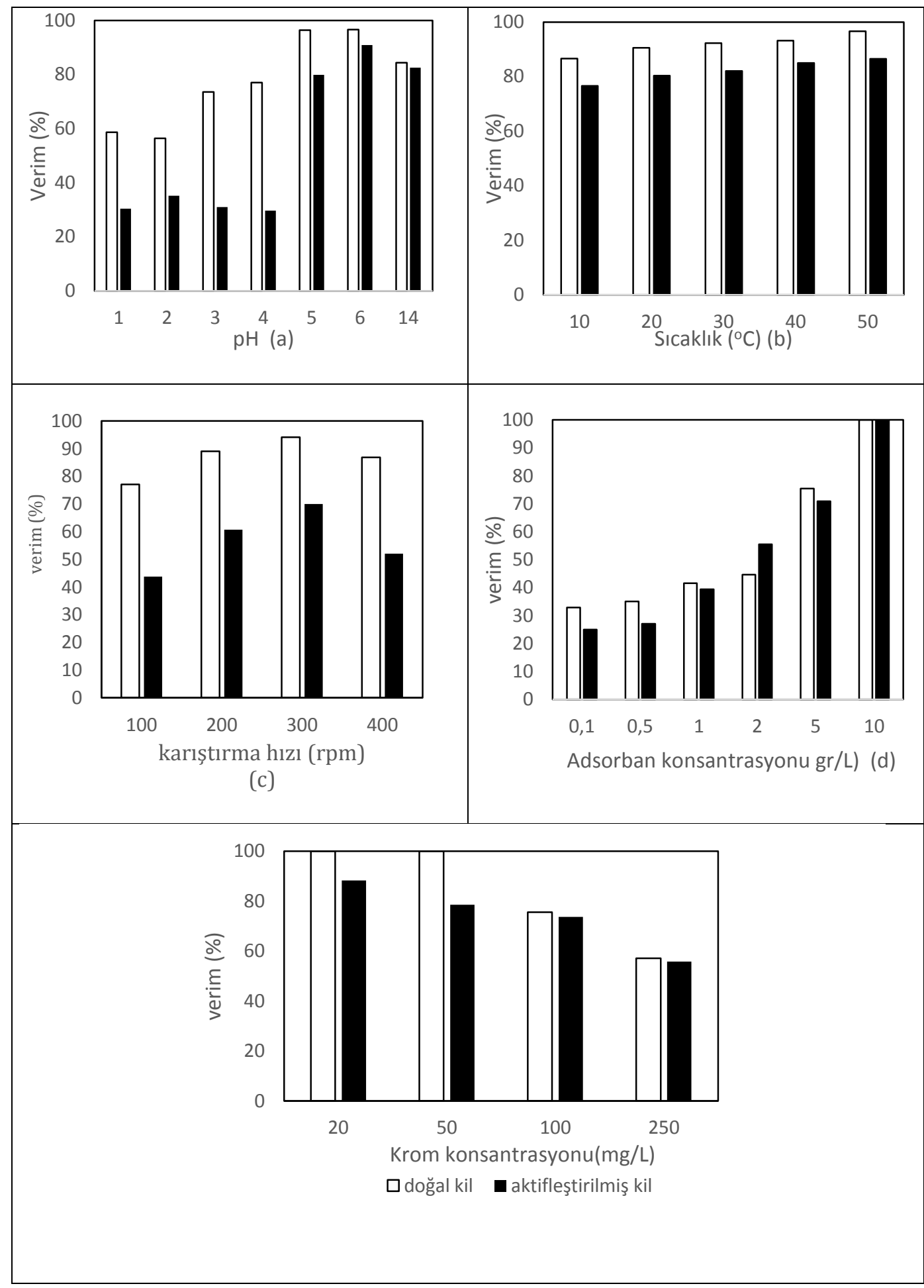

Şekil 7. Doğal montmorillonit ve aktifleştirilmiş montmorillonit ile krom(III) gideriminin karşılaştırılması 
Ş. İrdemez vd. / Montmorillonit Mineral Kayacı Kullanılarak Atıksulardan Krom (III) İyonlarının Giderimi Etki Eden Parametrelerin İncelemesi

\section{Tartışma ve Sonuç}

$\mathrm{Bu}$ çalışmada sentetik olarak hazırlanmış atıksulardan krom(III) iyonlarınin adsorpsiyonla giderimi ve adsorpsiyon üzerine etkili olan parametreler incelenmiștir. Adsorban olarak Erzurum'un Narman ilçesinden çlkarılan doğal kil montmorillonit adsorban olarak kullanılmıștır. Deneysel çalıșmada adsorpsiyon kinetiği üzerine pH'ın etkisi, başlangıç krom konsantrasyonu, sicaklık, karıştırma hızı ve adsorban miktarının etkisi incelenmiștir. Ayrıca adsorban olarak kullanılan kil aktifleștirme işlemine tabi tutularak aynı çalışmalar tekrar edilmiştir.

Çalışmada pH'nın etkisi öncelikle düşük pH'larda ve $\mathrm{pH} 14$ 'de incelenmiştir. Zira pH 6 ile 13 arası pH'larda krom(III) iyonları suda bulunan hidroksit $\left(\mathrm{OH}^{-}\right)$ iyonları ile birleşerek çökelmekte ve adsorpsiyon olayı gerçekleșmemektedir. Çalışmalar sonunda en uygun $\mathrm{pH}$ değerinin 5 olduğu tespit edilerek diğer parametreler bu pH'da çalışılmıştır.

Daha sonra yapılan sicaklık denemelerinde adsorpsiyon hızının sıcaklık artmasıyla arttığı, adsorpsiyonun dengeye gelme süresinin kısaldığı ve verimin de yükseldiği görülmüştür.

Daha sonra çalışmada kullanılan adsorban miktarının etkisi ve başlangıç krom(III) konsantrasyonunun etkisi incelenmiștir. Adsorban miktarının artmasının adsorpsiyon verimini ve hızını artırdığı, krom konsantrasyonun artmasının ise adsorpsiyon verimini düşürdüğü tespit edilmiştir.

Yapılan karıștırma hızının etkisi denemelerinde $100,200,300$ ve 400 rpm karıștırma hızlarında çalışmalar yapılmıştır. 100 ve $200 \mathrm{rpm}$ için verimin düşük olduğu, 400 rpm karıştırma hızı için ise deney süresinde desorpsiyonun arttığı tespit edilmiş ve en uygun karıştırma hızının 300 rpm olduğu belirlenmiştir.

Aynı çalışmalar asitle muamele edilerek aktifleştirme işlemine tabi tutulmuş adsorban ile de yapılmıştır. Fakat aktifleştirme işleminin montmorillonit için verimde bir artışa neden olmadığı hatta verimi olumsuz olarak etkilediği tespit edilmiştir. Ayrıca bu adsorban ile yapılan çalışmalarda yüksek miktarda desorpsiyon meydana gelmiş ve denge konsantrasyonunun belirlenmesi zorlaşmıştır. $\mathrm{Bu}$ durum aktifleştirme işleminin kilin por yapısını bozduğu ve adsorbe olan moleküllerin kolayca tekrar suya geçtiği izlenimini doğurmuştur.

Yapılan bu çalışma sonunda doğada bol miktarda bulunan ve maliyeti düşük olan montmorillonit mineralinin sulardan ağır metal gideriminde adsorban olarak kullanılabileceğini göstermiștir.

\section{Kaynakça}

[1] Taştan, B. E., Ertuğrul, S. Dönmez, G., "Effective Bioremoval of Reactive Dye And Heavy Metals Byaspergillus Versicolor" Bioresearch Technology, 101, 870-876, 2010.

[2] Zayed A. M. And Norman T., "Chromium in The Environments: Factors Affecting Biological Remediation" Plant and Soil, 249, 139-156, 2003.

[3] Asri Ötüken F., Sönmez S., 2010, Ağır Metal Toksititesinin Bitki Metabolizması Üzerine Etkileri, 
Ş. İrdemez vd. / Montmorillonit Mineral Kayacı Kullanılarak Atıksulardan Krom (III) İyonlarının Giderimi Etki Eden Parametrelerin İncelemesi

Akdeniz Üniversitesi Ziraat Fakültesi Toprak Bölümü, 2010.

[4] Fenglian F., Wang Q., "Removal of heavy metalsi ons from wastewater: reviw" Journal of Environmental Engineering, 92, 3, 407-418, 2011.

[5] Babel S., Kurniawan T. A., LowCost Adsorbents for Heavy Metals Uptake from Contaminated Water: A Review", J Hazard Mater, 97, 1-3, 219-243, 2003.

[6] Günaydın, F., Özer, A., Altundoğan, H.S., Erdem, M., Tümen, F., "The Removal of Cr(VI) from Aqueous Solutions Using Zinc Extraction Residue", Environ Technol, 20, 405-411, 1999.

[7] Barlett, R. J. and Kimble, J. M., "Behaviour of Chromium in SolisII, Hexavalent Forms", J Environ Qual, 5, 383-386, 1976.

[8] Jiang J., Xu R., Wang Y., Zhao A., "The Mechanism of Chromate Sorption by Three Variable Charge Soils", Chemosphere, 71, 8, 1469-1475, 2008.

[9] Griffin, R.A., Au, K. A. and Frost, A.A., " Effect of pH Adsorption of Chromium from landfill lechate by clay minerals" Journal of Environmental Sci,ence and Health, 12, 431-449, 1977.

[10] Huang, C. and Wu, M., "Chromium Removal by Carbon Adsorption", Journal WPFC,47:10, 2437-2446, 1975.

[11] Chen, W., Parette, R., Zou, J., Cannon, F. S., Dempsey, "Arsenic removal by ironmodified activated carbon" Water Research, 41,1851-1858, 2007.
[12] Kaneko, S., Tsukamoto, K. and Imoto, F., "Adsorption Characteristics of Chromium (VI) on Coprecipitated Silica Titania Gel”, Nippon Kagaku Kaishi, 9, 1978.

[13] Majdan, M., Maryuk O., Pikus S., Olszewska E., Kwiatkowski R., Skrzypek H.,"Equilibrium, FTIR, Scanning Electron Microscopy and Small Wide Angle XRayScattering Studies of Chromates Adsorption on Modified Bentonite",J Mol Struct, 740, 1-3, 203-211, 2005.

[14] Toprak, R., Girgin İ., "Aktifleștirilmiş Klinoptilonit ile Deri Sanayi Atıksularından Kromun Giderilmesi", Turk J Engin Environ Sci, 24, 343-351, 2000.

[15] Krishna, B. S., Murty, D. S. R., Prakash, B. S. J., "Arsenic Removal By İron-Modified Activated Carbon" Applied Clay Science, 20, 65-71, 2001.

[16] Günaydın, F., Özer, A., Altundoğan, H.S., Erdem, M., Tümen, F., "The Removal of Cr(VI) from Aqueous Solutions Using Zinc Extraction Residue", Environ Technol, 20, 405-411, 1999.

[17] Erdem, M., Altundoğan, H. S., Tümen, F., " Removal of Hexavalent chromium by usng heat-activated bauxite" Minerals Engineering, 17, 1045-1052, 2004.

[18] Tümen, F., Arslan, N. ve Bildik, M., "Kırmızı Çamur Kullanılarak Sulu Çözeltilerden Cr(VI) Uzaklaştırılması", Çevre-87 Sempozyumu, EBSO-İzmir, 1987.

[19] Samson O., Tella A. C., “ Removal and Hexavalent chromium from 
Ş. İrdemez vd. / Montmorillonit Mineral Kayacı Kullanılarak Atıksulardan Krom (III) İyonlarının Giderimi Etki Eden Parametrelerin İncelemesi

aqueous solutions by adsorption on modified groundnut hull" Beni-Suef University Journal of Basic and Applied Sciences, 5, 4 ,2016.

[20] Fellenz N., Perez- Alonso F. J., Martin P. P., Garcia-Fierro J. L: , Bengoa J. F., Marchetti S. G. And Rojas S., " Chromium (VI)removal from water by means of adsorption- reduction at the surface of amino -functionalized MCM-41 sorbents" 239, 138-146, 2017.

[21] Turan, T., "Pilot süt fabrikası atıksularının membran biyoreaktörde arıtılması" Atatürk Üniversitesi Fen Bilimleri Enstitüsü, Çevre Bilimleri Anabilim dalı, Erzurum, 2012.

[22] Özyay, G., “ Yüksek Lisans Tezi, Atatürk Üniversitesi Çevre Mühendisliği Anabilim Dalı, Erzurum, 2012. 